\title{
Evaluation of the effects of androgen receptor gene trinucleotide repeats and prostate-specific antigen gene polymorphisms on prostate cancer
}

\author{
D. Alptekin ${ }^{1}$, M. Izmirli ${ }^{1}$, Y. Bayazit ${ }^{2}$, H.U. Luleyap ${ }^{1}$, M.B. Yilmaz', \\ B. Soyupak ${ }^{2}$, M.A. Erkoc ${ }^{1}$ and Z. Tansug ${ }^{2}$ \\ ${ }^{1}$ Department of Medical Biology, Faculty of Medicine, \\ University of Cukurova, Adana, Turkey \\ ${ }^{2}$ Department of Urology, Faculty of Medicine, \\ University of Cukurova, Adana, Turkey \\ Corresponding author: D. Alptekin \\ E-mail: alptekin@cu.edu.tr
}

Genet. Mol. Res. 11 (2): 1424-1432 (2012)

Received April 13, 2011

Accepted December 13, 2011

Published May 18, 2012

DOI http://dx.doi.org/10.4238/2012.May.18.1

\begin{abstract}
The number of trinucleotide repeats [CAG (coding for polyglutamine), GGC (coding for polyglycine)] in the first exon of the androgen receptor (AR) gene and prostate-specific antigen (PSA) gene androgen response element IA/G polymorphism are both related to prostate cancer prognosis. We investigated whether these genomic changes occur in the AR and PSA genes, which are usually found in individuals with prostate cancer, of Turkish patients and to find out their distribution in the population. We used PCR and PCR-RFLP assays for AR and PSA genes, respectively, to detect molecular changes in 44 prostate cancer patients. Our findings indicate that individuals with prostate cancer tend to have around $18 \mathrm{CAG}$ trinucleotide repeats. We observed significant differences between 22 controls, 33 benign prostate hyperplasia (BPH) patients and 44 adenocarcinoma patients for long CAG repeats. However, we did not find any significant differences in GGC repeats between controls, BPH and adenocarcinoma patients $(\mathrm{P}=0.408)$. We also did not observe significant
\end{abstract}


differences in the PSA A/G polymorphism frequency between controls, $\mathrm{BPH}$ and adenocarcinoma patients $(\mathrm{P}=0.483)$. In conclusion, $\mathrm{CAG}$ and GGC repeats in the AR and PSA gene polymorphisms may be associated with prostate cancer risk and $\mathrm{BPH}$ in the Turkish population.

Key words: Prostate cancer; Androgen receptor (AR) gene; Prostate-specific antigen (PSA) gene; Trinucleotide repeats

\section{INTRODUCTION}

In men, prostate cancer ranks second to lung cancer in cancers that are likely to result in death. Recent studies have shown that prostate cancer has a genetic basis, which could be important for inheritance of the cancer to male offspring. These genes are the androgen receptor (AR) gene, prostate-specific antigen (PSA) gene, $5 \alpha$-reductase type II (SRD5A2) gene, cytochrome P450c17 $\alpha$ (CYP17) gene, cytochrome P4503A4 (CYP3A4) gene, and elaC homolog 2 (ELAC2) genes (Gsur et al., 2002). Mutations in the AR and PSA genes are thought to be responsible for the development of prostate cancer (Stanford et al., 1997; Tavtigian et al., 2001; Gsur et al., 2002, 2004; Nenonen et al., 2010).

The development and progression of prostate cancer is affected by androgens. The actions of androgens are mediated via an AR, which is a ligand-dependent transcription factor. The single-copy human AR gene is located at the Xq11.2-q12 chromosome X (Lubahn et al., 1989; Monroe et al., 1995; Xu et al., 1998; Lange et al., 1999) and its activity is regulated by testosterone and dihydrotestosterone. In prostate cancer, AR may show similar activity to the members of other steroid receptor families (Evans, 1988). The DNA-binding domain in the first exon of AR has a zinc finger domain that may bind to androgen response element(s) (ARE) at the $\mathrm{N}$ terminal, and to androgen at the $\mathrm{C}$ terminal. This exon contains several polymorphic repetitions of which CAG (coding for polyglutamine) and GGC (coding for polyglycine) show the most variability. Normally there are 8-35 CAG repeats, the average being 20 . These repeats form a polyglutamine chain on the AR protein that can bind to DNA to regulate transcription. An increase in the number of CAG repeats may interfere with the transcription of the AR gene. However, transcriptional activity may increase when repeats are high. Therefore, shorter repeats may comprise higher risk for prostate cancer (Irvine et al., 1995; Zeegers et al., 2004; Mishra et al., 2005; Krishnaswamy et al., 2006; Rodríguez-González et al., 2009).

The effect of the variation in the length of the GGC tract on AR activity is unclear, but it has been thought that the GGC trinucleotide repeats range from 10 to 30 the transcriptional activity of the AR gene (Gao et al., 1996; Zeegers et al., 2004; Mishra et al., 2005; Krishnaswamy et al., 2006). However, to date, no relationship has been established between the length of the polyglycine region and infertility (Tut et al., 1997). Epidemiological studies have shown that a decrease in the number of repeats in both sequences constitutes a major risk for the occurrence of prostate cancer (Stanford et al., 1997; Hakimi et al., 1997; Platz et al., 1998; Sartor et al., 1999). Indeed, prostatectomy has been recommended for individuals, who have a decreased number of repeats, as the prostate cancer risk is considerably higher in this individual (Hardy et al., 1996; Bratt et al., 1999).

The PSA gene, a member (hK3) of the human kallikrein (hK) gene family, is located at the 19q13.41 chromosome 19 (Klobeck et al., 1989; Lilja, 2003). It encodes a glycoprotein 
containing 240 amino acids, also known as serine protease (33 kDa). Since PSA secretion is regulated by androgens via AR-dependent pathways, an increase in the amount of androgen in turn induces PSA secretion from the prostate epithelium (Medeiros et al., 2002; Rao et al., 2003). Therefore, ARE mutations interfering with the PSA regulation lead to an increase in PSA secretion. An increase in PSA secretion will eventually cause prostate cells to develop into tumor tissue (Xu et al., 1998; Lange et al., 1999).

There are three different ARE sites in the promoter region of the PSA gene, which are known to regulate PSA gene transcriptional activity. These AREs are ARE I, ARE II and ARE III (Rao et al., 2003). Androgen response element I contains two allele variants (AGAACAnnnAGT $\underline{G C T}$ and AGAACAnnnAGT $\underline{\mathbf{A} C T)}$. The AR binds these different alleles with different affinities. Therefore, these variations in affinities are important in the development of prostate cancer risk (Xue et al., 2000, 2001). In a study carried out on males with prostate cancer in Portugal, ratios of AA, AG and GG genotypes were determined as 43,41 and $16 \%$, respectively (Medeiros et al., 2002). The same genotypes were detected as 5, 31 and 64\% in healthy Japanese males (Wang et al., 2003). Another study carried out in China in randomized samples of the same genotypes was determined as 5, 26 and 69\% (Liu et al., 2003). In addition to that, the GG genotype is reported to have a higher risk of prostate cancer especially among younger men (Binnie et al., 2005). The purpose of this study was to examine the relationship between benign prostate hyperplasia (BPH), malignant prostate cancer (adenocarcinoma) and polymorphisms in two genes involved in the androgen pathway, the CAG and GGC trinucleotide repeat length in the AR gene and the A/G polymorphism at the ARE I region of the PSA gene.

\section{MATERIAL AND METHODS}

This study was performed on 33 patients with BPH (61.06 \pm 11.263 mean age), 44 patients with malignant (adenocarcinoma) cancer (64.24 \pm 8.89 mean age) and 22 controls (58.14 \pm 9.671 mean age) with no known cancer. Patients were referred to the Urology Department at Çukurova University, Adana, Turkey. Blood $(5 \mathrm{~mL})$ was obtained from each patient. Genomic DNA was isolated employing the standard salting-out DNA isolation method (Sambrook et al., 1989) and then amplified with gene specific primers. For the CAG repeats, the polymerase chain reaction $(\mathrm{PCR})$ products of the $\mathrm{AR}$ gene were obtained using a mixture containing $10 \mathrm{pmol}$ from each primer: 5'-TCC AGAATC TGT TCC AGA GCG TGC-3' (forward) and 5'-GCT GTG AAG GTT GCT GTT CCT CAT-3' (reverse) (Xu et al., 1998), 2 mM MgCl, 0.2 mM dNTPs, 2.5 U Taq polymerase, and 100-500 ng DNA sample. After the initial denaturation of the reaction mixture at $95^{\circ} \mathrm{C}$ for $3 \mathrm{~min}$, amplification was achieved by 30 cycles at $95^{\circ} \mathrm{C}$ for $30 \mathrm{~s}, 60^{\circ} \mathrm{C}$ for $30 \mathrm{~s}$ and $72^{\circ} \mathrm{C}$ for $30 \mathrm{~s}$, and a final extension at $72^{\circ} \mathrm{C}$ for $10 \mathrm{~min}(\mathrm{Xu}$ et al., 1998). For the GGC repeats, the PCR products of the AR gene were obtained using a mixture containing $10 \mathrm{pmol}$ from each primer: 5'-TCC TGG CAC ACT CTC TTC AC-3' (forward) and 5'-GCC AGG GTA CCA CAC ATC AGG T-3' (reverse) (Xu et al., 1998), 2 mM MgCl, 0.2 mM dNTPs, 2.5 U Taq polymerase, and 100-500 ng DNA sample. After initial denaturation of the reaction mixture at $95^{\circ} \mathrm{C}$ for $3 \mathrm{~min}$, amplification was achieved by 30 cycles at $95^{\circ} \mathrm{C}$ for $30 \mathrm{~s}, 60^{\circ} \mathrm{C}$ for $30 \mathrm{~s}$ and $72^{\circ} \mathrm{C}$ for $30 \mathrm{~s}$, and a final extension at $72^{\circ} \mathrm{C}$ for $10 \mathrm{~min}$ (Xu et al., 1998). The PCR products were loaded onto $10 \%$ polyacrylamide gels and electrophoresed at $100 \mathrm{~V}$ for 90 min, stained in $\mathrm{EtBr}$ for $5 \mathrm{~min}$, visualized by using a UviTech Gel documentation system and then evaluated.

The ARE in the promoter region of the PSA gene was amplified in a PCR mixture con- 
taining 10 pmol from each primer: 5'-TTG TAT GAA GAA TCG GGG ATC GT-3' (forward) and 5'-TCC CCC AGG AGC CCT ATA AAA-3' (reverse), $2 \mathrm{mM} \mathrm{MgCl}, 0.2 \mathrm{mM}$ dNTPs, 2.5 $\mathrm{U}$ Taq polymerase, and 100-500 ng DNA sample for each reaction. After the initial denaturation of the reaction mixture at $95^{\circ} \mathrm{C}$ for $3 \mathrm{~min}$, amplification was achieved by 30 cycles at $95^{\circ} \mathrm{C}$ for $30 \mathrm{~s}, 59^{\circ} \mathrm{C}$ for $30 \mathrm{~s}$ and $72^{\circ} \mathrm{C}$ for $30 \mathrm{~s}$, and a final extension at $72^{\circ} \mathrm{C}$ for $10 \mathrm{~min}$ (Xue et al., 2000). The A/G polymorphism at the ARE I (AGA ACA GCA AGT GCT AGC) region was detected by the RFLP (restriction fragment length polymorphism) method. Restriction digestion of the PCR products was performed by using the NheI enzyme (Xue et al., 2000). After digestion, the original PCR products and restriction digestion products were loaded onto $10 \%$ polyacrylamide gels and electrophoresed at $100 \mathrm{~V}$ for $90 \mathrm{~min}$, stained in $\mathrm{EtBr}$ for $5 \mathrm{~min}$, visualized by using a UviTech Gel documentation system and then evaluated. As a result of our evaluation we observed a 300-bp band for homozygous AA, 300- and 150-bp bands for heterozygous AG and a 150-bp band for homozygous GG.

The analysis of the data was performed by the SPSS software (version 11.5). The Pearson chi-square test was used to compare ratios and $\mathrm{P}<0.05$ was accepted as statistically significant. Additionally, we estimated the area under the curve (AUC) and corresponding $95 \%$ confidence interval $(\mathrm{CI})$ for the association between each repeat length and prostate cancer. In our analysis, we used 18 cut-off points for the CAG repeats but could not determine the cut-off points for analyzing the GGC repeats. We therefore analyzed the GGC repeats with the Kruskal-Wallis test.

\section{RESULTS}

Our study comprises prostate cancer patients from the Cukurova region, Turkey. In the present study, the number of trinucleotide repeats in the first exon of the AR gene (CAG and GGC repeats) and PSA gene polymorphisms were investigated. This study was performed on 33 BPH patients (61.06 \pm 11.263 mean age), 44 adenocarcinoma patients (64.24 \pm 8.689 mean age) and 22 healthy controls $(58.14 \pm 9.671$ mean age). When analyzing the $\mathrm{CAG}$ repeats, we used 18 as a cut-off point $(\mathrm{AUC}=0.659 \pm 0.055 ; 95 \% \mathrm{CI}=0.552-0.766 ; \mathrm{P}=0.007)$ (Table 1$)$. The $\mathrm{AR}$ CAG repeat sizes were categorized as "short" ( $\leq 18$ CAG repeats) or "long" ( $>18$ CAG repeats).

Table 1. Coordinates of the curve.
\begin{tabular}{lcc} 
\\
\hline Positive if greater than or equal to & Sensitivity & Specificity \\
\hline 8.00 & 1.000 & 1.000 \\
9.50 & 0.977 & 0.945 \\
11.00 & 0.977 & 0.927 \\
12.50 & 0.977 & 0.855 \\
13.50 & 0.977 & 0.836 \\
14.50 & 0.932 & 0.800 \\
15.50 & 0.909 & 0.727 \\
16.50 & 0.773 & 0.564 \\
17.50 & 0.727 & 0.473 \\
18.50 & 0.591 & 0.400 \\
19.50 & 0.523 & 0.400 \\
20.50 & 0.432 & 0.218 \\
21.50 & 0.318 & 0.164 \\
22.50 & 0.205 & 0.091 \\
23.50 & 0.114 & 0.055 \\
24.50 & 0.000 & 0.036 \\
26.00 & 0.000 & 0.000 \\
\hline
\end{tabular}


Frequencies of the AR CAG repeats in controls, BPH and adenocarcinoma patients are shown in Table 2. The difference between controls, BPH and adenocarcinoma patients was statistically significant $(\mathrm{P}=0.03 ; \mathrm{P}<0.05)$. We also observed that the frequencies of the CAG repeats increase as the adenocarcinoma develops. The control, BPH and adenocarcinoma groups have different long CAG repeat frequencies, which are 14.6, 31.2 and $54.2 \%$, respectively.

\begin{tabular}{|c|c|c|c|c|c|}
\hline Genotypes & Control $(\mathrm{N}=22)$ & $\mathrm{BPH}(\mathrm{N}=33)$ & Adenocarcinoma $(\mathrm{N}=44)$ & Total $(\mathrm{N}=99)$ & $P$ value \\
\hline Short repeat & $\begin{array}{l}15 \\
29.4 \%\end{array}$ & $\begin{array}{l}18 \\
35.3 \%\end{array}$ & $\begin{array}{l}18 \\
35.3 \%\end{array}$ & $\begin{array}{c}51 \\
100 \%\end{array}$ & $\begin{array}{r}0.03 \\
<0.05\end{array}$ \\
\hline Long repeat & $\begin{array}{c}7 \\
14.6 \%\end{array}$ & $\begin{array}{l}15 \\
31.2 \%\end{array}$ & $\begin{array}{l}26 \\
54.2 \%\end{array}$ & $\begin{array}{c}48 \\
100 \%\end{array}$ & \\
\hline
\end{tabular}

$\mathrm{BPH}=$ benign prostate hyperplasia.

During GGC repeat analyses, we could not determine a specific cut-off point $(\mathrm{AUC}=0.573 \pm 0.087 ; 95 \% \mathrm{CI}=0.403-0.743 ; \mathrm{P}=0.386)$. Therefore, the mean of the GGC repeats of the groups has been determined with the Kruskal-Wallis test. Control, BPH and adenocarcinoma groups have means of $28.75,21.31$ and $27.39 \%$, respectively. We did not observe any difference between the controls, $\mathrm{BPH}$ and adenocarcinoma patients $(\mathrm{P}=$ 0.408; P > 0.05).

In the present study, we examined an $\mathrm{A} / \mathrm{G}$ polymorphism in the promoter region of the PSA gene (Table 3). We found the percentages of AA, AG and GG variants to be as follows: the AA variant in controls $14.6 \%$, in $\mathrm{BPH} 42.7 \%$ and in adenocarcinoma patients 42.7\%; the AG variant in controls $25.7 \%$, in BPH $17.1 \%$ and in adenocarcinoma patients $57.2 \%$; the GG variant in controls $11.1 \%$, in BPH $22.2 \%$ and in adenocarcinoma patients $66.7 \%$. However, we could not establish a statistically significant correlation for the $\mathrm{A} / \mathrm{G}$ polymorphism in the PSA gene between controls, BPHs and adenocarcinoma patients ( $\mathrm{P}$ $=0.483 ; \mathrm{P}>0.05)$.

Table 3. Distribution of PSA A/G polymorphism between controls, BPH and adenocarcinomas.
\begin{tabular}{lccccc} 
PSA A/G genotypes & Control $(\mathrm{N}=11)$ & $\mathrm{BPH}(\mathrm{N}=11)$ & Adenocarcinoma $(\mathrm{N}=29)$ & Total $(\mathrm{N}=51)$ & P value \\
\hline AA & 1 & 3 & 3 & 7 & 0.483 \\
& $14.6 \%$ & $42.7 \%$ & $62.7 \%$ & $100 \%$ & $>0.05$ \\
AG & 9 & 6 & 20 & 35 & \\
& $25.7 \%$ & 2 & $67.2 \%$ & $100 \%$ & \\
GG & 1 & $22.2 \%$ & $66.7 \%$ & $100 \%$ & \\
& $11.1 \%$ & &
\end{tabular}

$\mathrm{BPH}=$ benign prostate hyperplasia.

When PSA genotypes and CAG repeats were assessed together, it was found that the short CAG repeat frequencies of the AA genotype was $16.7 \%$, AG genotype was $58.3 \%$ and GG genotype was $25.0 \%$. It was also found that the long CAG repeat frequencies of the AA genotype was $12.5 \%$, AG genotype was $83.3 \%$ and GG genotype was $4.2 \%$ (Table 4). Nevertheless, we did not observe any statistically significant differences between CAG repeats and PSA A/G polymorphisms $(\mathrm{P}=0.09 ; \mathrm{P}>0.05)$. 
Table 4. Distribution of PSA A/G polymorphism between short and long CAG repeats.

\begin{tabular}{lccc}
\hline PSA A/G genotypes & Short repeat $(\mathrm{N}=24)$ & Long repeat $(\mathrm{N}=24)$ & P value \\
\hline AA & 4 & 3 & 0.09 \\
& $16.7 \%$ & $12.5 \%$ & $>0.05$ \\
AG & 14 & 20 & \\
& $58.3 \%$ & $83.3 \%$ & \\
GG & 6 & 1 & \\
& $25.0 \%$ & $2.2 \%$ & \\
Total & 24 & $100 \%$ & \\
& $100 \%$ & & \\
\hline
\end{tabular}

\section{DISCUSSION}

The AR gene contains two polymorphic trinucleotide repeats within the transactivation domain of the first exon, which are the CAG and the GGC repeats. The length of the CAG repeat is inversely related to AR transcriptional activity. Shorter CAG repeats have been associated with prostate cancer risk as well as an aggressive form of the disease. The relationship between the length of GGC repeats and prostate cancer risk, however, is not clearly understood (Irvine et al., 1995; Zeegers et al., 2004; Mishra et al., 2005; Krishnaswamy et al., 2006).

Androgens are critical for the development and progression of prostate cancer. It has been suggested by Ross et al. (1999) that variation in transcriptional activity in the AR is related to polymorphic CAG repeats affecting prostate carcinogenesis. Short CAG repeats may be associated with a higher level of transactivation, thus increasing the risk of prostate cancer (Ross et al., 1999). The number of CAG repeats associated with prostate cancer as a continuous variable was $0.97(95 \% \mathrm{CI}=0.95-1.03)$, suggesting a $3 \%$ decrease in prostate cancer risk for each additional CAG repeat (Stanford et al., 1997) but this result was not statistically significant. Gsur et al. (2002) reported that these data provide no evidence for an association between prostate cancer and CAG repeat length.

In the present study, we observed statistically significant differences between controls, $\mathrm{BPH}$ and adenocarcinoma for long CAG repeats $(\mathrm{P}=0.03 ; \mathrm{P}<0.05)$. Our results may imply that longer CAG repeats might be associated with a higher level of receptor transactivation, since the number of CAG repeats increases in the BPH and adenocarcinoma patients compared to controls with the highest increase in adenocarcinoma patients.

Lack of a uniform model of analysis also makes these studies difficult to compare. Giovannucci et al. $(1997,1999)$ examined CAG repeat length as a continuous variable and also compared men with $\leq 18$ repeats, and men with $\geq 26$ repeats. Irvine et al. (1995) and Stanford et al. (1997) used the median number of 22 to divide their population for analysis. Lange et al. (1999) declared that it is unclear whether these studies examined multiple cut-off points and were appropriately corrected for multiple testing. In our study, we determined a cut-off point of $\leq 18$ as important for evaluating the data. The association of the short CAG repeats and prostate cancer incidence, as well as the variety of different models, made it possible to interpret the data.

There are similar uncertain data for the GGC repeats and prostate cancer, with some (Stanford et al., 1997; Hakimi et al., 1997; Platz et al., 1998), but not all (Correa-Cerro et al., 1999) studies reporting an association, while other studies suggest that longer AR GGC repeats may increase risk among men with a positive family history of prostate cancer. Cicek et al. (2004) did not find any association between the GGC repeat length and prostate cancer risk.

The PSA gene is a target of the AR. For PSA gene transcription to occur, the AR must 
interact with ARE I in the PSA gene promoter. It has been mentioned that the PSA gene homozygote for the $\mathrm{G}$ allele is associated with a higher PSA concentration and prostate cancer (Gsur et al., 2002). Wang et al. (2003) stated that the PSA polymorphism may not be associated with the risk of prostate cancer development, progression and BPH in Japanese men.

Gsur et al. (2002) reported that they found a significant influence of the ARE I PSA polymorphism on prostate cancer risk when calculating the combination of the AG and GG genotypes versus the AA genotype, suggesting that the $G$ allele has a protective effect. When men carried one $\mathrm{G}$ allele, the prostate cancer risk decreased about $63 \%$. Otherwise, in a case analysis according to the Gleason score, the GG genotype was associated with a more aggressive disease phenotype. PSA seems to have stimulatory effects on prostatic cell proliferation.

Xue et al. (2000) reported in a study of non-Hispanic white men, comprising 57 prostate cancer cases and 156 controls, that subjects with the GG genotype were at significantly increased risk for advanced but not localized prostate cancer. After cross-classification by PSA and AR genotypes they found that men having the PSA GG genotype in combination with short $\mathrm{CAG}$ alleles, defined as $\leq 20 \mathrm{CAG}$ repeats, have $\mathrm{a} \geq 5$-fold increase of prostate cancer risk. The frequency of the AA polymorphism is low in the normal population (5\%) (Wang et al., 2003; Liu et al., 2003); however, it was found to be high in individuals diagnosed with prostate cancer (43\%) (Giovannucci et al., 1999; Medeiros et al., 2002). We did not observe a statistically significant difference between controls, BPH and adenocarcinoma for the PSAA/G polymorphism $(\mathrm{P}=0.483 ; \mathrm{P}>0.05)$. Furthermore, we also did not find a statistically significant difference between the PSA A/G polymorphism and CAG trinucleotide repeats in the AR gene. However, we observed higher GG variant frequencies in the short CAG repeats compared to AA and AG variants. These data were in accordance with the findings of Xue et al. (2000).

In conclusion, results of our studies conducted on prostate cancer patients in Cukurova region may imply that the PSA A/G polymorphism is not related to prostate cancer; however, CAG trinucleotide repeat expansion size is adversely related to prostate cancer risk.

\section{ACKNOWLEDGMENTS}

Research supported by the Çukurova University Research (Grants \#TF.2004BAP32 and \#TF2008 BAP10).

\section{REFERENCES}

Binnie MC, Alexander FE, Heald C and Habib FK (2005). Polymorphic forms of prostate specific antigen and their interaction with androgen receptor trinucleotide repeats in prostate cancer. Prostate 63: 309-315.

Bratt O, Borg A, Kristoffersson U, Lundgren R, et al. (1999). CAG repeat length in the androgen receptor gene is related to age at diagnosis of prostate cancer and response to endocrine therapy, but not to prostate cancer risk. Br. J. Cancer 81: 672-676.

Cicek MS, Conti DV, Curran A, Neville PJ, et al. (2004). Association of prostate cancer risk and aggressiveness to androgen pathway genes: SRD5A2, CYP17, and the AR. Prostate 59: 69-76.

Correa-Cerro L, Wohr G, Haussler J, Berthon P, et al. (1999). (CAG) CAA and GGN repeats in the human androgen receptor gene are not associated with prostate cancer in a French-German population. Eur. J. Hum. Genet. 7: 357-362.

Evans RM (1988). The steroid and thyroid hormone receptor superfamily. Science 240: 889-895.

Gao T, Marcelli M and McPhaul MJ (1996). Transcriptional activation and transient expression of the human androgen receptor. J. Steroid Biochem. Mol. Biol. 59: 9-20.

Giovannucci E, Stampfer MJ, Krithivas K, Brown M, et al. (1997). The CAG repeat within the androgen receptor gene and its relationship to prostate cancer. Proc. Natl. Acad. Sci. U. S. A. 94: 3320-3323. 
Giovannucci E, Stampfer MJ, Chan A, Krithivas K, et al. (1999). CAG repeat within the androgen receptor gene and incidence of surgery for benign prostatic hyperplasia in U.S. physicians. Prostate 39: 130-134.

Gsur A, Feik E and Madersbacher S (2004). Genetic polymorphisms and prostate cancer risk. World J. Urol. 21: 414-423.

Gsur A, Preyer M, Haidinger G, Zidek T, et al. (2002). Polymorphic CAG repeats in the androgen receptor gene, prostatespecific antigen polymorphism and prostate cancer risk. Carcinogenesis 23: 1647-1651.

Hakimi JM, Schoenberg MP, Rondinelli RH, Piantadosi S, et al. (1997). Androgen receptor variants with short glutamine or glycine repeats may identify unique subpopulations of men with prostate cancer. Clin. Cancer Res. 3: 1599-1608.

Hardy DO, Scher HI, Bogenreider T, Sabbatini P, et al. (1996). Androgen receptor CAG repeat lengths in prostate cancer: correlation with age of onset. J. Clin. Endocrinol. Metab. 81: 4400-4405.

Irvine RA, Yu MC, Ross RK and Coetzee GA (1995). The CAG and GGC microsatellites of the androgen receptor gene are in linkage disequilibrium in men with prostate cancer. Cancer Res. 55: 1937-1940.

Klobeck HG, Combriato G, Schulz P, Arbusow V, et al. (1989). Genomic sequence of human prostate specific antigen (PSA). Nucleic Acids Res. 17: 3981.

Krishnaswamy V, Kumarasamy T, Venkatesan V, Shroff S, et al. (2006). South Indian men with reduced CAG repeat length in the androgen receptor gene have an increased risk of prostate cancer. J. Hum. Genet. 51: 254-257.

Lange EM, Chen H, Brierley K, Perrone EE, et al. (1999). Linkage analysis of 153 prostate cancer families over a 30-cM region containing the putative susceptibility locus HPCX. Clin. Cancer Res. 5: 4013-4020.

Lilja H (2003). Biology of prostate-specific antigen. Urology 62: 27-33.

Liu J, Zhang JS, Young CY and Kao PC (2003). Polymorphisms of prostate-specific antigen gene promoter: determination from cord blood collected on filter paper. Ann. Clin. Lab. Sci. 33: 429-434.

Lubahn DB, Brown TR, Simental JA, Higgs HN, et al. (1989). Sequence of the intron/exon junctions of the coding region of the human androgen receptor gene and identification of a point mutation in a family with complete androgen insensitivity. Proc. Natl. Acad. Sci. U. S. A. 86: 9534-9538.

Medeiros R, Morais A, Vasconcelos A, Costa S, et al. (2002). Linkage between polymorphisms in the prostate specific antigen ARE1 gene region, prostate cancer risk, and circulating tumor cells. Prostate 53: 88-94.

Mishra D, Thangaraj K, Mandhani A, Kumar A, et al. (2005). Is reduced CAG repeat length in androgen receptor gene associated with risk of prostate cancer in Indian population? Clin. Genet. 68: 55-60.

Monroe KR, Yu MC, Kolonel LN, Coetzee GA, et al. (1995). Evidence of an X-linked or recessive genetic component to prostate cancer risk. Nat. Med. 1: 827-829.

Nenonen H, Björk C, Skjaerpe P-A, Giwercman A, et al. (2010). CAG repeat number is not inversely associated with androgen receptor activity in vitro. Mol. Hum. Reprod. 16: 153-157.

Platz EA, Giovannucci E, Dahl DM, Krithivas K, et al. (1998). The androgen receptor gene GGN microsatellite and prostate cancer risk. Cancer Epidemiol. Biomark. Prev. 7: 379-384.

Rao A, Chang BL, Hawkins G, Hu JJ, et al. (2003). Analysis of G/A polymorphism in the androgen response element I of the PSA gene and its interactions with the androgen receptor polymorphisms. Urology 61: 864-869.

Rodríguez-González G, Cabrera S, Ramirez-Moreno R, Bilbao C, et al. (2009). Short alleles of both GGN and CAG repeats at the exon-1 of the androgen receptor gene are associated to increased PSA staining and a higher Gleason score in human prostatic cancer. J. Steroid Biochem. Mol. Biol. 113: 85-91.

Ross RK, Coetzee GA, Pearce CL, Reichardt JK, et al. (1999). Androgen metabolism and prostate cancer: establishing a model of genetic susceptibility. Eur. Urol. 35: 355-361.

Sambrook J, Fritsch EF and Maniatis T (1989). Analysis and Cloning of Eukaryotik Genomic DNA. In: Molecular Cloning: a Laboratory Manual (Sambrook J, Fritsch EF and Maniatis T, eds.). 2nd edn. Cold Spring Harbor Laboratory Press, Cold Spring Harbor, 9.34-9.51.

Sartor O, Zheng Q and Eastham JA (1999). Androgen receptor gene CAG repeat length varies in a race-specific fashion in men without prostate cancer. Urology 53: 378-380.

Stanford JL, Just JJ, Gibbs M, Wicklund KG, et al. (1997). Polymorphic repeats in the androgen receptor gene: molecular markers of prostate cancer risk. Cancer Res. 57: 1194-1198.

Tavtigian SV, Simard J, Teng DH, Abtin V, et al. (2001). A candidate prostate cancer susceptibility gene at chromosome 17p. Nat. Genet. 27: 172-180.

Tut TG, Ghadessy FJ, Trifiro MA, Pinsky L, et al. (1997). Long polyglutamine tracts in the androgen receptor are associated with reduced trans-activation, impaired sperm production, and male infertility. J. Clin. Endocrinol. Metab. 82: 3777-3782.

Wang LZ, Sato K, Tsuchiya N, Yu JG, et al. (2003). Polymorphisms in prostate-specific antigen (PSA) gene, risk of prostate cancer, and serum PSA levels in Japanese population. Cancer Lett. 202: 53-59.

Xu J, Meyers D, Freije D, Isaacs S, et al. (1998). Evidence for a prostate cancer susceptibility locus on the X chromosome. Nat. Genet. 20: 175-179. 
Xue W, Irvine RA, Yu MC, Ross RK, et al. (2000). Susceptibility to prostate cancer: interaction between genotypes at the androgen receptor and prostate-specific antigen loci. Cancer Res. 60: 839-841.

Xue W, Goetze GA, Ross RK, Irvine R, et al. (2001). Genetic determinants of serum prostate-specific antigen levels in healthy men from a multiethnic cohort. Cancer Epidemiol. Biomark. Prev. 10: 575-579.

Zeegers MP, Kiemeney LA, Nieder AM and Ostrer H (2004). How strong is the association between CAG and GGN repeat length polymorphisms in the androgen receptor gene and prostate cancer risk? Cancer Epidemiol. Biomark. Prev. 13: 1765-1771. 